\title{
ChemComm
}

\section{Nickel-catalysed carboxylation of organoboronates $\dagger$}

Cite this: Chem. Commun., 2014 50, 8010

Received 14th May 2014

Accepted 5th June 2014

DOI: $10.1039 / c 4 c c 03650 f$

www.rsc.org/chemcomm

A nickel/N-heterocyclic carbene (NHC) catalysed carboxylation of aryl-, heteroaryl- and alkenylboronates, affording the corresponding carboxylic acids, has been developed. This transformation proceeds under one atmosphere of $\mathrm{CO}_{2}$ with a broad range of substrates and exhibits good functional group compatibility.

Carbon dioxide $\left(\mathrm{CO}_{2}\right)$ is one of the most promising carbon sources for the production of fine chemicals as it is abundant, non-toxic, cheap and renewable. ${ }^{1}$ Amongst the numerous reports regarding $\mathrm{CO}_{2}$ fixation mediated by metal centres, significant efforts have targeted the development of efficient and direct carboxylation protocols. ${ }^{2}$ Highly reactive organometallic reagents, such as organolithium and Grignard reagents, are the historical, yet still typical starting materials for nucleophilic carboxylation, since they are reactive enough to overcome the inherent thermodynamic stability of $\mathrm{CO}_{2}$. However, their narrow functional group compatibility hampers their general and practical use. Consequently, carboxylation using a widely adaptable reagent is highly desirable. ${ }^{3-9}$ In the last decade, the transition metal catalysed carboxylation of organoboronates with $\mathrm{CO}_{2}$ has been achieved using $\mathrm{Rh},{ }^{3} \mathrm{Cu}^{4}$ and $\mathrm{Ag}^{5}$ catalysts (Scheme 1, path A).

Yorimitsu, Oshima and Dong have described a nickelcatalysed carboxylation employing organozinc reagents with $\mathrm{CO}_{2}$, and proposed that an Aresta-type complex was involved in the catalytic cycle (Scheme 1, path $\mathrm{B}, \mathbf{M}^{\prime}=\mathrm{Zn}$ ). ${ }^{7,10}$ While these reactions were restricted mostly to alkylzinc reagents, ${ }^{11}$ nickel-based systems offer fascinating possibilities in terms of adopting a mechanism distinct from those reported with other transition metals (Scheme 1). Nickel catalysis typically proceeds through oxidative cyclization of $\mathrm{CO}_{2}$ by zero-valent nickel,

\footnotetext{
${ }^{a}$ EaStCHEM School of Chemistry, University of St Andrews, North Haugh, St Andrews, KY16 9ST, UK. E-mail: snolan@st-andrews.ac.uk

${ }^{b}$ Chemistry Department, College of Science, King Saud University, Riyadh 11451, Saudi Arabia

$\dagger$ Electronic supplementary information (ESI) available: Experimental details and characterization data for all new compounds and all products. CCDC 998382. For ESI and crystallographic data in CIF or other electronic format see DOI: 10.1039/ c4cc03650f
}

followed by a transmetalation and reductive elimination (Scheme 1, path B). Other transition metal catalysts normally involve transmetalation followed by insertion of $\mathrm{CO}_{2}$ into a metal-carbon bond without a change in metal oxidation state (Scheme 1, path A).

Herein, we report a methodology for the carboxylation of organoboronates under one atmosphere of $\mathrm{CO}_{2}$ catalysed by a well-defined nickel pre-catalyst having a specific $\mathrm{N}$-heterocyclic carbene ligand (Scheme 1, path $\mathrm{B}, \mathrm{M}^{\prime}=\mathrm{B}$ ). This reaction presents broad functional group compatibility and simple reaction conditions. Moreover, to the best of our knowledge, the nickel-catalysed coupling of organoboron reagents with $\mathrm{CO}_{2}$ has not been reported to date.

Very recently, we reported the synthesis and characterization of novel [ $\mathrm{Ni}(\mathrm{NHC})($ allyl)Cl] complexes, bearing the flexible yet bulky NHC ligands $\operatorname{IPr}^{*}$ and $\operatorname{IPr}^{* \mathrm{OMe}}$; these complexes are useful catalysts for $\mathrm{C}-\mathrm{N}$ and $\mathrm{C}-\mathrm{S}$ coupling reactions. ${ }^{12}$ Although they generate $\mathrm{Ni}(0)$ active species easily with the assistance of the steric pressure of the bulky NHC ligand and the labile $\eta^{3}$-allyl moiety, these complexes possess good stability. In this context, we began to explore the possibility of an efficient carboxylation methodology using this catalytic nickel system in conjunction with organoboron reagents and $\mathrm{CO}_{2}$ as the reaction partners.

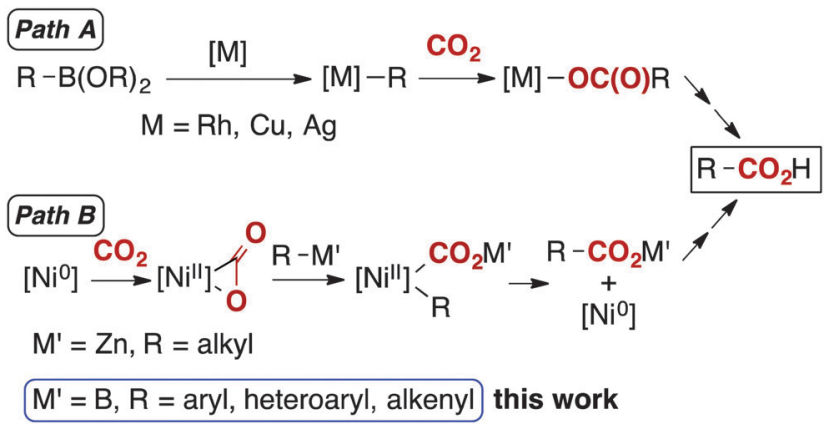

Scheme 1 Two distinct pathways for the metal-catalysed carboxylation of less-nucleophilic organometallic reagents. 
Table 1 Nickel-catalysed carboxylation of $2 \mathbf{a}^{a}$

\begin{tabular}{|c|c|c|c|c|}
\hline \multirow[b]{2}{*}{ Entry } & \multicolumn{2}{|c|}{ i precatalyst } & aq. $\mathrm{HCl}$ & \\
\hline & $\mathrm{Ni}$ pre-catalyst & $T\left({ }^{\circ} \mathrm{C}\right)$ & Solvent & $y^{b}(\%)$ \\
\hline 1 & [Ni(IPr)(all)Cl] (1a) & 100 & Toluene & 7 \\
\hline 2 & [Ni(SIPr)(all)Cl] (1b) & 100 & Toluene & 45 \\
\hline 3 & {$[\mathrm{Ni}(\mathrm{IMes})($ all)Cl] (1c) } & 100 & Toluene & 15 \\
\hline 4 & [Ni(SIMes)(all)Cl] (1d) & 100 & Toluene & 10 \\
\hline 5 & {$\left[\mathrm{Ni}\left(\mathrm{IPr}^{*}\right)(\right.$ all $\left.) \mathrm{Cl}\right](\mathbf{1 e})$} & 100 & Toluene & Quant. \\
\hline 6 & $1 \mathrm{e}$ & 80 & Toluene & 56 \\
\hline $7^{c}$ & $1 \mathrm{e}$ & 100 & Toluene & 15 \\
\hline 8 & {$\left[\mathrm{Ni}\left(\mathrm{IPr}^{*}\right)(\mathrm{Cp}) \mathrm{Cl}\right](\mathbf{1 f})$} & 100 & Toluene & 0 \\
\hline 9 & {$\left[\mathrm{Ni}\left(\mathrm{IPr}^{* \mathrm{OMe}}\right)(\right.$ all $\left.) \mathrm{Cl}\right](\mathbf{1 g})$} & 100 & Toluene & Quant. \\
\hline 10 & $1 \mathrm{~g}$ & 80 & Toluene & 26 \\
\hline $11^{d}$ & {$\left[\mathrm{Ni}(\operatorname{cod})_{2}\right] / \mathrm{IPr}^{*}$} & 100 & Toluene & Quant. \\
\hline 12 & $1 e$ & 80 & Dioxane & 37 \\
\hline 13 & 1e & 80 & CPME & 47 \\
\hline 14 & $1 \mathrm{e}$ & 80 & DMA & 0 \\
\hline 15 & $1 \mathrm{e}$ & 80 & DCE & 0 \\
\hline $16^{e}$ & $1 \mathrm{e}$ & 100 & Toluene & 0 \\
\hline $17^{f}$ & $1 e$ & 100 & Toluene & 10 \\
\hline $18^{g}$ & - & 100 & Toluene & 0 \\
\hline $19^{h}$ & $1 \mathrm{e}$ & 100 & Toluene & 0 \\
\hline $20^{i}$ & $1 e$ & 100 & Toluene & 0 \\
\hline
\end{tabular}

${ }^{a}$ Reaction conditions: $2 \mathrm{a}(0.2 \mathrm{mmol}, 1.0$ equiv. $), \mathrm{CO}_{2}(1 \mathrm{~atm}), \mathrm{Ni}$ precatalyst (5 mol\%), $\mathrm{KO}^{t} \mathrm{Bu}(0.24 \mathrm{mmol})$, solvent $(1.0 \mathrm{~mL}), 15 \mathrm{~h} .{ }^{b}$ Yield determined by ${ }^{1} \mathrm{H}$ NMR spectroscopic analysis of crude product after acidic work up using 1,2-diphenylethane as an internal standard; average of two runs. ${ }^{c}$ With $1.0 \mathrm{~mol} \%$ of 1 e. ${ }^{d}$ With $5.0 \mathrm{~mol} \%$ of $\left[\mathrm{Ni}(\mathrm{cod})_{2}\right]$ and $6.0 \mathrm{~mol} \%$ of IPr*. ${ }^{e}$ With $0.24 \mathrm{mmol}$ of CsF instead of $\mathrm{KO}^{t} \mathrm{Bu} .{ }^{f}$ With $0.03 \mathrm{mmol}$ of $\mathrm{KO}^{t} \mathrm{Bu} .{ }^{g}$ Without Ni precatalyst. ${ }^{h} 0.24 \mathrm{mmol}$ of $\mathrm{KOH}$ used instead of $\mathrm{KO}^{t} \mathrm{Bu} .{ }^{i} 0.24 \mathrm{mmol}$ of $\mathrm{K}_{2} \mathrm{CO}_{3}$ used instead of $\mathrm{KO}^{t} \mathrm{Bu}$.

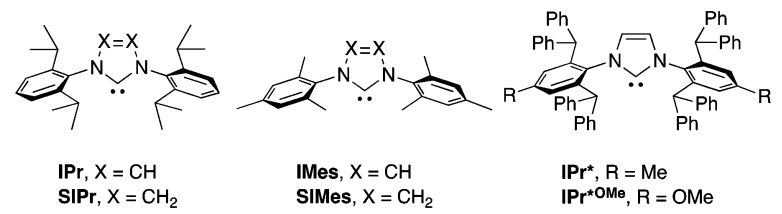

Fig. 1 Structures of $\mathrm{NHC}$ ligands used in this study.

We began our survey by screening the reactivity of nickel precatalysts $\mathbf{1 a}-\mathbf{g}$, as depicted in Table 1. [Ni(NHC)(allyl)Cl] complexes bearing less sterically demanding NHCs (IPr, SIPr, IMes and SIMes, see Fig. 1 for key structural features of NHC used in this study) showed poor to moderate reactivities (entries 1-4). For example, the reaction of boronate 2a using $[\mathrm{Ni}(\mathrm{IPr})($ allyl) $\mathrm{Cl}]$ as precatalyst gave the carboxylation product $3 \mathrm{a}$ in only $7 \%$ NMR conversion. ${ }^{13}$ The catalytic activity was drastically shifted by a judicious selection of the NHC ligand. Indeed, the reactions using the bulkier IPr*-based ligands ( $\operatorname{IPr}^{*}$ and $\operatorname{IPr}^{*} \mathrm{OMe}$ ) afforded the corresponding carboxylic acids quantitatively (entries 5 and 9). At $80{ }^{\circ} \mathrm{C}$, the $\operatorname{IPr}^{*}$ ligand showed higher reactivity than $\operatorname{IPr}^{*} \mathrm{OMe}$ (entries 6 and 10). The effect of the steric hindrance may very well result in an improvement of the stability of the active species or in the acceleration of one of the catalytic steps. Other observations concerning the optimized reaction conditions are to be noted: a $5 \mathrm{~mol} \%$ catalyst loading is required for excellent conversion (entry 5 vs. 7); the analogous nickel complex with a Cp moiety, instead of an allyl group, showed no activity (entry 8$) ;{ }^{12 a}$ a catalytic

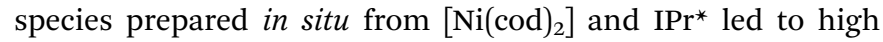
conversion (entry 11); ${ }^{14}$ ethers could be used but polar or chlorinated solvents gave no conversion (entries 12-15); despite its ability to activate boron reagents, CsF displays no reactivity as a base, (entry 16). ${ }^{3,4 a}$ The use of hydroxides and carbonates also gave no conversion (entries 19 and 20). When a sub-stoichiometric amount of $\mathrm{KO}^{t} \mathrm{Bu}$ was used, the product was formed substoichiometrically (entry 17) and carboxylation did not proceed in the absence of the nickel pre-catalyst (entry 18).

Importantly, possible side-reactions such as homocoupling or protodeborylation were not observed and the starting boronate was the only recovered material when reactions did not proceed efficiently to product. Other arylboron reagents such as boronic acids, pinacolates, and potassium trifluoroborates were tested but resulted in almost no reaction. ${ }^{13,15}$ Thus, conditions employed in entry 5 were selected as the optimum reaction settings.

We next evaluated the carboxylation of a range of aryl- and heteroarylboronates with $\mathrm{CO}_{2}$ under these optimized conditions. As shown in Table 2, $p$-anisic acid (3a), benzoic acid (3b) and $p$-toluic acid (3c) were obtained in excellent yields (entries 1-3). In addition, this nickel-catalysed carboxylation tolerated a variety of functional groups at the para position of the arylboronate reagent: examples include silyl ether, $\mathrm{CF}_{3}$ and tertiary amino groups, as well as halides (entries 4-8).

Notably, electrophilic and base-sensitive functionalities were also compatible, giving the corresponding benzoic acid derivatives $\mathbf{3 i}$ (90\%) and $\mathbf{3 j}$ (97\%), respectively, while leaving the

Table 2 Substrate scope of the nickel-catalysed carboxylation ${ }^{a}$

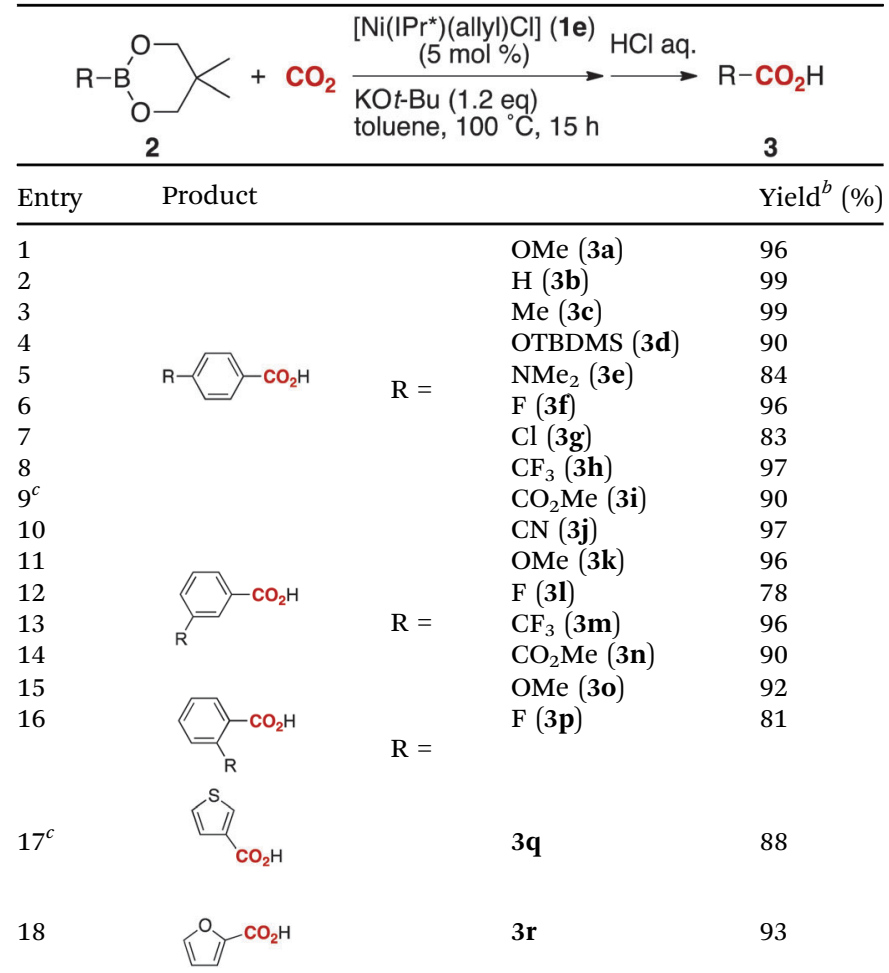

${ }^{a}$ Reaction conditions: 2 ( $\left.0.4 \mathrm{mmol}\right), \mathrm{CO}_{2}$ (1 atm), $1 \mathrm{e}(5 \mathrm{~mol} \%)$, and $\mathrm{KO}^{t} \mathrm{Bu}(0.48 \mathrm{mmol})$ in toluene $(2.0 \mathrm{~mL})$ at $100{ }^{\circ} \mathrm{C}$ for 15 hours. ${ }^{b}$ Yield of isolated product; average of two runs. ${ }^{c} 10 \mathrm{~mol} \% \mathbf{1 e}$. 
ester and nitrile moieties untouched (entries 9 and 10). This transformation was also applicable to both electron-rich and electron-deficient substituents in the meta position (entries 11-14). The current limitation of the method lies with the poor tolerance of ortho-substituted arylboronates. For example, the reaction of the neopentylgycolate of $o$-tolylboronic acid resulted in no reaction. Although the reaction proved to be sensitive to proximal steric bulk, $o$-anisic acid (3o) and 2-fluorobenzoic acid (3p) could be synthesised ( $92 \%$ and $81 \%$ respectively) (entries 15 and 16). Heteroaromatic boronate $\mathbf{2 q}$ reacted with $\mathrm{CO}_{2}$ to provide 3 -thenoic acid (3q) in $88 \%$ yield with $10 \mathrm{~mol} \%$ catalyst (entry 17 ). Boronate $2 \mathbf{r}$ was more reactive, affording 2 -furoic acid (3r) in 93\% yield (entry 18). The protocol was successfully extended to alkenylboron reagents (Table 3 ). ${ }^{16}$ Boronates having a conjugated $\pi$-system $\mathbf{4 a}$ and non-conjugated $\mathbf{4 b}$ reacted efficiently to afford the corresponding $\alpha, \beta$-unsaturated carboxylic acids $\mathbf{5 a}$ and $\mathbf{5 b}$ in $85 \%$ and $92 \%$ yield, respectively. exo-Olefinic boronate $4 \mathbf{c}$ also showed good reactivity (75\%).

As there is such a profound influence of the boron reagents, initial studies focused on the alkoxide base and how it could modify the boron reagent. It was originally thought that the role of $\mathrm{KO}^{t} \mathrm{Bu}$ was to activate the boronates for transmetalation. Indeed, the reaction between 2 and $\mathrm{KO}^{t} \mathrm{Bu}$ gave the corresponding aryltrialkoxyborate 6, quantitatively (eqn (1), see ESI $\dagger$ for more details). This boron quaternization proceeds smoothly at room temperature and reached completion within 30 minutes as monitored by NMR spectroscopy. ${ }^{13,17}$ The atom connectivity in $6 \mathbf{f}$ was unambiguously confirmed by X-ray analysis on single crystals (Fig. 2).

Table 3 Nickel-catalysed carboxylation of alkenylboronates $\mathbf{4}^{a, b}$

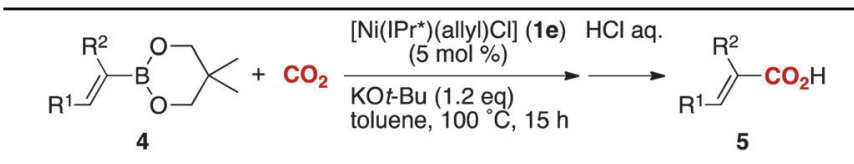

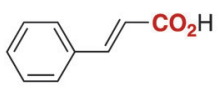

$85 \%(5 a)$

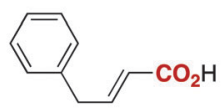

$92 \%(\mathbf{5 b})^{c}$

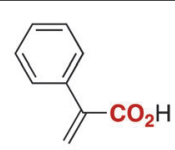

$75 \%(5 c)$
${ }^{a}$ Reaction conditions: $4(0.4 \mathrm{mmol}), \mathrm{CO}_{2}(1 \mathrm{~atm}), 1 \mathrm{e}(5 \mathrm{~mol} \%)$, and $\mathrm{KO}^{t} \mathrm{Bu}$ $(0.48 \mathrm{mmol})$ in toluene $(2.0 \mathrm{~mL})$ at $100{ }^{\circ} \mathrm{C}$ for 15 hours unless otherwise noted. ${ }^{b}$ Yield of isolated product; average of two runs. ${ }^{c} 10 \mathrm{~mol} \% \mathbf{1 e}$.

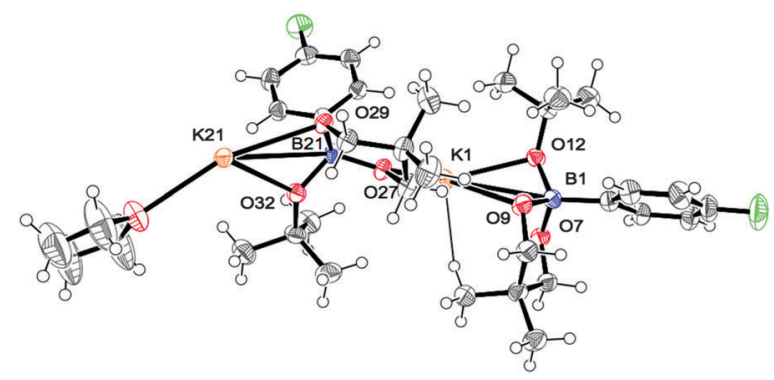

Fig. 2 Molecular structure of $6 f:(6 f)_{2} \cdot$ THF.
The reactivity of the borate $\mathbf{6 f}$ with $\mathrm{CO}_{2}$ under nickel catalysis was then examined. Isolated $\mathbf{6 f}$ was treated with $\mathrm{CO}_{2}$ in the presence of $5 \mathrm{~mol} \%$ of $1 \mathrm{e}$ and $7 \mathrm{~mol} \%$ of $\mathrm{KO}^{t} \mathrm{Bu}$ (eqn (2)), and the reaction afforded $>95 \%$ conversion to $3 \mathbf{f}$. In addition, the reaction proceeds with slightly lower reactivity in the absence of $\mathrm{KO}^{t} \mathrm{Bu}$ (eqn (3)). If a nickel(0) precursor is used, entirely base-free conditions can be achieved (61\% conversion, eqn (4)).
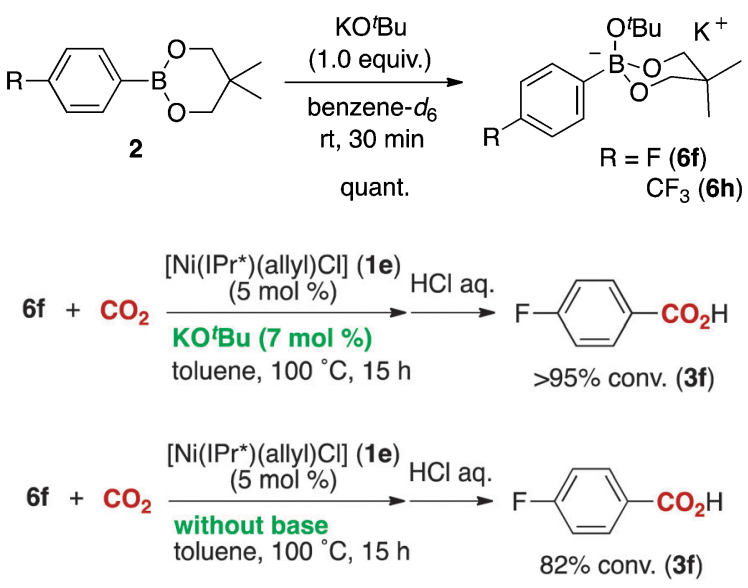

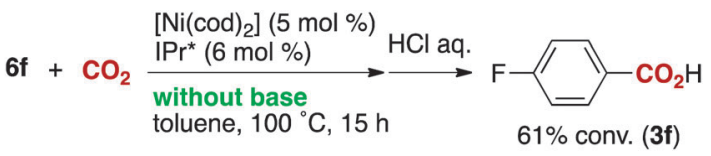

These results support our hypothesis that organoborates 6 are the reactive species in this reaction.

In summary, we have developed a novel Ni-catalysed strategy for $\mathrm{CO}_{2}$ incorporation using organoboron reagents. IPr*-based ligands show exceptional reactivity for this transformation. Substituted boronates with various functionalities are easily accessible and can be coupled with $\mathrm{CO}_{2}$ using nickel catalysis. The substrate scope is complementary to the reaction of organozinc reagents, which is mainly suitable for alkylzinc reagents. Ongoing mechanistic and catalytic studies are aimed at understanding the critical role of the ligand in this and related catalytic transformations.

We thank the ERC (Advanced Researcher award-FUNCAT, CO2Chem) and King Saud University for funding and the EPSRC NMSSC in Swansea for mass spectrometric analyses. SPN is a Royal Society Wolfson Research Merit Award holder.

\section{Notes and references}

1 For reviews regarding $\mathrm{CO}_{2}$ fixation, see: (a) T. Sakakura, J.-C. Choi and H. Yasuda, Chem. Rev., 2007, 107, 2365-2387; (b) M. Aresta and A. Dibenedetto, Dalton Trans., 2007, 2975-2992; (c) Carbondioxide as Chemical Feedstock, ed. M. Aresta, Wiley-VCH, Weinheim, 2010; (d) M. Mikkelsen, M. Jorgensen and F. C. Krebs, Energy Environ. Sci., 2010, 3, 43-81; (e) N. Kielland, C. J. Whiteoak and A. W. Kleij, Adv. Synth. Catal., 2013, 355, 2115-2138; $(f)$ M. Aresta, A. Dibenedetto and A. Angelini, Chem. Rev., 2013, 114, 1709-1742; $(g)$ C. Maeda, Y. Miyazaki and T. Ema, Catal. Sci. Technol., 2014, 4, 1482-1497.

2 For reviews on metal-catalysed carboxylation, see: $(a)$ A. Correa and R. Martín, Angew. Chem., Int. Ed., 2009, 48, 6201-6204; (b) R. Martín and A. W. Kleij, ChemSusChem, 2011, 4, 1259-1263; (c) K. Huang, C.-L. Sun and Z.-J. Shi, Chem. Soc. Rev., 2011, 40, 2435-2452; (d) M. Cokoja, C. Bruckmeier, B. Rieger, W. A. Herrmann and F. E. Kühn, Angew. Chem., Int. Ed., 2011, 50, 8510-8537; (e) Y. Tsuji and T. Fujihara, Chem. Commun., 2012, 48, 9956-9964; 
( $f$ ) L. Zhang and Z. Hou, Chem. Sci., 2013, 4, 3395-3403; (g) X. Cai and B. Xie, Synthesis, 2013, 3305-3324.

3 K. Ukai, M. Aoki, J. Takaya and N. Iwasawa, J. Am. Chem. Soc., 2006, 128, 8706-8707.

4 (a) J. Takaya, S. Tadami, K. Ukai and N. Iwasawa, Org. Lett., 2008, 10, 2697-2700; (b) T. Ohishi, M. Nishiura and Z. Hou, Angew. Chem., Int. Ed., 2008, 47, 5792-5795; (c) P. J. Riss, S. Lu, S. Telu, F. I. Aigbirhio and V. W. Pike, Angew. Chem., Int. Ed., 2012, 51, 2698-2702; (d) W. Wang, G. Zhang, R. Lang, C. Xia and F. Li, Green Chem., 2013, 15, 635-640.

5 X. Zhang, W.-Z. Zhang, L.-L. Shi, C.-X. Guo, L.-L. Zhang and X.-B. Lu, Chem. Commun., 2012, 48, 6292-6294.

6 For Pd-catalysed carboxylation of allylstannanes, see: (a) M. Shi and K. M. Nicholas, J. Am. Chem. Soc., 1997, 119, 5057-5058; (b) R. Johansson and O. F. Wendt, Dalton Trans., 2007, 488-492; (c) J. Wu and N. Hazari, Chem. Commun., 2011, 47, 1069-1071.

7 For Ni- and Pd-catalysed carboxylation of organozinc reagents, see: (a) H. Ochiai, M. Jang, K. Hirano, H. Yorimitsu and K. Oshima, Org. Lett., 2008, 10, 2681-2683; (b) C. S. Yeung and V. M. Dong, J. Am. Chem. Soc., 2008, 130, 7826-7827.

8 For Cu-catalysed carboxylation of alkylboranes, see: $(a) \mathrm{H}$. Ohmiya, M. Tanabe and M. Sawamura, Org. Lett., 2011, 13, 1086-1088; (b) T. Ohishi, L. Zhang, M. Nishiura and Z. Hou, Angew. Chem., Int. Ed., 2011, 50, 8114-8117.

9 For other selected Ni-catalysed carboxylation processes, see: $(a) \mathrm{M}$. Takimoto and M. Mori, J. Am. Chem. Soc., 2002, 124, 10008-10009; (b) C. M. Williams, J. B. Johnson and T. Rovis, J. Am. Chem. Soc., 2008,
130, 14936-14937; (c) T. Fujihara, K. Nogi, T. Xu, J. Terao and Y. Tsuji, J. Am. Chem. Soc., 2012, 134, 9106-9109; (d) T. León, A. Correa and R. Martin, J. Am. Chem. Soc., 2013, 135, 1221-1224; (e) A. Correa, T. León and R. Martin, J. Am. Chem. Soc., 2014, 136, 1062-1069.

10 M. Aresta, F. C. Nobile, V. G. Albano, E. Forni and M. Manassero, Chem. Commun., 1975, 636-637.

11 Only phenylzinc as an arylzinc reagent could be used, as an exception. See ref. 7.

12 (a) A. R. Martin, D. J. Nelson, S. Meiries, A. M. Z. Slawin and S. P. Nolan, Eur. J. Org. Chem., 2014, 3127-3313; (b) A. R. Martin, Y. Makida, S. Meiries, A. M. Z. Slawin and S. P. Nolan, Organometallics, 2013, 32, 6265-6270.

13 See ESI $\dagger$ for experimental details.

14 Other $\mathrm{Ni}(0)$ precursors were also tested: for example, using $\left[\mathrm{Ni}(\mathrm{SIPr})\left(\eta^{6}\right.\right.$-toluene $\left.)\right]$ as catalyst resulted in a carboxylic acid yield of $32 \%$; see: Y. Hoshimoto, Y. Hayashi, H. Suzuki, M. Ohashi and S. Ogoshi, Organometallics, 2014, 33, 1276-1282.

15 When pinacolboranes were used, trace amounts of homocoupling products were detected by ${ }^{1} \mathrm{H}$ NMR spectroscopy.

16 This class of products can be obtained by hydrocarboxylation of alkynes: see: T. Fujihara, T. Xu, K. Semba, J. Terao and Y. Tsuji, Angew. Chem., Int. Ed., 2011, 50, 523-527 and references therein.

17 Similar activation pathways have been reported: $(a)$ B. Saito and G. C. Fu, J. Am. Chem. Soc., 2007, 129, 9602-9603; (b) Y. Yamamoto, M. Takizawa, X.-Q. Yu and N. Miyaura, Angew. Chem., Int. Ed., 2008, 47, 928-931; (c) K. L. Billingsley and S. L. Buchwald, Angew. Chem., Int. Ed., 2008, 47, 4695-4698. 